\title{
Internacionalização do ensino superior: um estudo na Universidade Federal de Santa Maria
}

Este estudo teve como objetivo analisar as práticas de internacionalização promovidas pela Universidade Federal de Santa Maria, identificando as razões que estimulam esse processo, assim como as ações e estratégias organizacionais e programáticas utilizadas para internacionalização, com base no modelo teórico de Knight (2004). Para tanto, realizou-se uma pesquisa qualitativa, de natureza descritiva, tendo como unidade de análise os Programas de Pós-Graduação com conceitos 6 e 7, avaliados pela Capes, os quais já apresentam significativo desempenho internacional. A primeira etapa da coleta de dados constituiu um estudo documental de informações disponíveis no site da instituição. Na segunda etapa, foram efetuadas entrevistas com 6 (seis) profissionais que participaram, direta ou indiretamente, do processo de internacionalização da universidade, utilizando como base para as entrevistas o roteiro de Miura (2006). A análise dos resultados apresentados neste estudo revelou que a UFSM, embora desenvolva a internacionalização com um crescente número de estudantes e professores em mobilidade acadêmica e um significativo número de convênios com instituições estrangeiras e associações com grupos estrangeiros, ainda apresenta fragilidades em suas estratégias organizacionais e programáticas, necessitando institucionalizar políticas de internacionalização na cultura da instituição.

\section{Internationalization of higher education: a study at the Federal University of Santa Maria}

This study aimed to analyze the internationalization practices promoted by the Federal University of Santa Maria, identifying the reasons that stimulate this process, as well as the organizational and programmatic actions and strategies used for internationalization, based on Knight's theoretical model (2004). To this end, a qualitative research was carried out, of a descriptive nature, having the Postgraduate Programs with concepts 6 and 7 as evaluated by Capes, which already have a significant international performance. The first stage of data collection was a documentary study of information available on the institution's website. In the second stage, interviews were conducted with 6 (six) professionals who participated, directly or indirectly, in the university's internationalization process, using Miura's (2006) script as the basis for the interviews. The analysis of the results presented in this study revealed that UFSM, although developing internationalization with an increasing number of students and professors in academic mobility and a significant number of agreements with foreign institutions and associations with foreign groups, still presents weaknesses in its organizational strategies and programmatic, needing to institutionalize internationalization policies in the institution's culture.

Keywords: Internationalization; Internationalization strategies; Academic mobility.

Topic: Planejamento, Estratégia e Competitividade

Reviewed anonymously in the process of blind peer.
Received: $10 / 12 / 2019$

Approved: 25/01/2020
Anieli Ebling Bulé (D)

Universidade Federal de Santa Maria, Brasil

http://lattes.cnpq.br/2233898993735616

http://orcid.org/0000-0003-4310-4750

anieli.bule@hotmail.com
Referencing this:

BULÉ, A. E.. Internacionalização do ensino superior: um estudo na Universidade Federal de Santa Maria. Revista Brasileira de Administração Científica, v.11, n.1, p.41-52, 2020. DOI: http://doi.org/10.6008/CBPC2179-684X.2020.001.0004 


\section{INTRODUÇÃO}

É possível observar o processo evolutivo internacional das políticas educacionais, que vem se manifestando em diferentes níveis e intensidades de acordo com os países e as regiões, tais mudanças educacionais têm refletido em grandes reestruturações escolares que afetam e são afetadas mundialmente (AKKARI, 2011). Sustentando esse crescimento está a expansão da escolarização por meio de modelos educacionais aceitos mundialmente, parcerias entre universidades, relações interculturais, intercâmbio de alunos e professores, contribuindo positivamente para a ampliação de conhecimentos e competências, crescimento econômico e intelectivo e desenvolvimento de práticas internacionais.

Esse processo de descentralização vem modificando o perfil das universidades, que por sua vez são pressionadas pelo ambiente a se tornarem mais flexíveis em seus preceitos e capazes de formar profissionais aptos às exigências mutáveis do mercado. A inserção do Brasil no conjunto estrangeiro tem sido cada vez maior. Segundo dados do Conselho Nacional de Desenvolvimento Científico e Tecnológico (CNPq) divulgados em 2013, o país é o que mais cresce no mundo em produções científicas, dispondo de $2,7 \%$ da produção científica mundial.

Dessa maneira, é possível verificar que diversos países vêm utilizando diferentes práticas, políticas, projetos e ações transnacionais para a reestruturação da educação superior; utilizando da colaboração acadêmica para a resolução dos complexos problemas da ciência e sociedade (SANTOS et al., 2012). Diante desse contexto, é possível verificar que as redes dentre instituições contribuem para a ampliação e desenvolvimento da capacidade inovadora das instituições. Relacionam-se essas mudanças no âmbito educacional com a economia, ou seja, com a comercialização da educação e fornecimento de ensino aos consumidores (alunos e pais), que podem optar livremente por melhores propostas e ofertas educativas (GOODSON, 2003)

Esse processo tem se evidenciado, em especial, pelo grande avanço da ciência e da intercomunicação, gerando a universalização do conhecimento e criando um ambiente de interdependências e inter-relações (AKKARI, 2011). Em geral, se pode constatar um processo evolutivo da escolarização desde meados dos anos 1950 (ILLICH, 1970), facilitando o desenvolvimento em nível internacional da educação (SCHRIEWER, 2004).

O fomento das inter-relações nos diferentes planos sociais ocorre devido às IES possuírem um papel primordial na formação de profissionais com alto nível de qualificação, na produção de conhecimento científico e na atração de capital humano que auxiliam na evolução, inovação e criação de tecnologias (CARNOY, 2002; OLIVEIRA, 2000).

Enfatizando benefícios das inter-relações entre instituições nacionais e internacionais, pois ambos terão benefícios com o aumento do volume e da qualidade da produção científica, assim como, com o desenvolvimento e qualificação dos programas de pós-graduação. É nesse contexto, que o conceito de internacionalização do ensino superior é abordado, reforçando uma temática já existente. Porém, somente em meados dos anos 1980, é que a internacionalização se tornou uma opção estratégica para o 
desenvolvimento das universidades (TAYLOR, 2010).

Dessa forma, considerando a internacionalização do ensino superior um processo complexo e partindo da premissa de que as razões, ações e estratégias de internacionalização ocorrem de forma diferenciada em cada IES, define-se como objetivo central da pesquisa, analisar as práticas de internacionalização promovidas pelos Programas de Pós-Graduação conceitos 6 e 7 da Universidade Federal de Santa Maria. Em termos específicos, este estudo almeja analisar as estratégias organizacionais e programáticas adotadas pela Universidade Federal de Santa Maria.

\section{REVISÃO TEÓRICA}

As instituições de ensino superior, juntamente com outras instituições científicas e profissionais, têm demonstrando grande capacidade de transformação e adaptação às transformações ocorridas mundialmente no âmbito tecnológico, social e cultural, representando assim um elemento determinante no desenvolvimento nacional, devido à capacidade de ensino, pesquisa e extensão (UNESCO, 2000; SANTOS et al., 2012).

A transmissão de conhecimento, de educação e de culturas entre estudantes e professores, através da mobilidade acadêmica, redes de inter-relacionamentos, círculos de pesquisas e projetos, descrevem o processo de internacionalização das instituições de ensino superior que buscam inserir, dentro do ambiente de aprendizado e de ensino, a dimensão internacional (KNIGHT, 2010).

Mudanças tecnológicas têm impactado a sociedade moderna, devido à facilidade de disseminação de informações e conhecimentos, através da internet, que possibilita a transmissão de estudos e pesquisas, possibilita a comunicação com os mais diversos pontos do planeta com grande facilidade e economia junto à educação a distância, disponibilizando aos alunos a facilidade do estudo, sem a necessidade de sua presença integral na universidade, sendo ponto importante para expansão internacional de programas acadêmicos (MIURA, 2006).

Os bancos de dados, a partir da utilização de informações disponíveis em websites e bases tecnológicas, trouxeram mais alcance e facilidade aos alunos na obtenção de bibliografia para o desenvolvimento de trabalhos, deixando de serem usados somente livros e materiais científicos de bibliotecas (MIURA, 2006, citado por HAWKINS et al., 1998). Para Lévy (1999), a tecnologia, acompanhando a evolução da sociedade, traz benefícios e acréscimos de aprendizado em relação ao ensino, entretanto, seu uso não pode ser indiscriminado.

As IES na sociedade moderna possuem a capacidade de promover a modificação, desenvolvimento e crescimento intelectual o que se configura como tema chave e de suma importância para o desenvolvimento das nações (NEVES, 2007). Segundo registros, o Brasil, no período colonial, foi proibido pela monarquia portuguesa de estabelecer universidades em seu território, ou seja, na maior colônia portuguesa; sendo o ensino religioso a única forma de educação com permissão limitada. Entretanto, quando filhos de autoridades necessitavam ou eram impostos a estudar, eram encaminhados para a Universidade de Coimbra em Portugal, para colar o grau em Leis ou Teologia (SANTOS et al., 2012). 
A consolidação do ensino superior iniciou por meio de faculdades e não por universidades; as primeiras instituições implantadas em território nacional foram de Medicina localizada no Rio de Janeiro e Bahia, e de Direito em São Paulo e Recife (SANTOS et al., 2012). Devido a uma visita do Rei Leopoldo da Bélgica ao Brasil, foi possível instituir a Universidade no país, em 1922, para que fosse concedido o título de Doutor Honoris Causa ao Rei, para suprir as conveniências do Rei Europeu e prestar-lhe homenagens acadêmicas (UNESCO, 2003).

Para que o ensino universitário no país pudesse ser usufruído, passaram-se mais de vinte anos, quando então os estados do Rio de Janeiro, Minas Gerais, Bahia e Recife puderam sediar de maneira pioneira, as universidades. Apesar da existência de cursos de ensino superior por todo o período de 1922 a 1934 , somente a precária instituição do Rio de Janeiro existia; somente nos anos 1960, é que os modelos de pesquisas científicas e tecnológicas chegaram aos Brasil (SANTOS et al., 2012; UNESCO, 2003).

Nos dias de hoje, os cursos e modalidades de ensino superior brasileiros estão dispostos em graduação, que competem a candidatos que tenham concluído o ensino médio ou equivalente e tenham sido classificados em processo seletivo; pós-graduação, com programas de mestrado e doutorado e cursos de especialização, sendo disponíveis a candidatos diplomados em cursos de graduação e que atendam às exigências das instituições de ensino; extensão, abertos a candidatos que atendam aos requisitos estabelecidos pelas instituições de ensino, podendo ser conferido certificado aos concluintes; e sequenciais que são organizados por campo de saber, de diferentes níveis de abrangência, abertos a candidatos que atendam aos requisitos estabelecidos pelas instituições de ensino, desde que tenham concluído o ensino médio ou equivalente. É imposto de maneira implícita e subentendida, que os cursos de graduação são caracterizados como profissionalizantes; quanto às modalidades, podem ser cursados presencialmente ou a distância (SANTOS et al., 2012).

A Avaliação Trienal 2013 demonstrou um crescimento de 23\% no número de Programas de PósGraduação no país; a região norte teve maior crescimento de cursos de mestrado e doutorado, $40 \%$, seguida pela região Centro-Oeste com $37 \%$ e Nordeste com 33\%. Sul e Sudeste, regiões com maior número de programas de pós-graduação, tiveram crescimento de $25 \%$ e $14 \%$, respectivamente. O Sistema Nacional de Pós-Graduação está se consolidando ainda mais, por meio da busca constante pela qualidade e melhorias.

Segundo o ex Ministro da Educação, Aloizio Mercadante, os resultados da avaliação apontam para a evolução do sistema de pós-graduação em direção à qualidade. Apesar de não haver mudanças significativas, apresenta uma trajetória constante de expansão e melhoria (CAPES, 2013). 0 crescimento da pós-graduação brasileira também pode ser percebido em outros indicadores, como a produção intelectual e no número de mestres e doutores titulados. Dados da produção intelectual apontam um aumento de $34 \%$ nas publicações de artigos em periódicos científicos, sendo 171.969 em 2012; e o número de estudantes que obtiveram título de mestre ou doutor saltou de 50.411 em 2010, para 60.910 em 2012 (CAPES, 2013).

Diversos autores propõem diferentes modelos para o processo de internacionalização, dentre os principais identificados na literatura estão Neave, o qual apresenta um modelo paradigmático para manutenção e administração da cooperação internacional. O segundo modelo, desenvolvido por Rudzki, tem 
uma abordagem mais pragmática às estratégias, e tenta fornecer um framework para avaliar os níveis de atividade internacional dentro das instituições. O modelo de Davies dá mais ênfase às estratégias organizacionais como um ponto de partida. O quarto modelo, por Van Dijk, é uma tentativa de aperfeiçoar o modelo de Davies descreveram esses quatro modelos. Entretanto, o quinto modelo é por Van Der Wende (1996) e resultou de um modelo projetado para o NUFFIC com base na abordagem de processo para a internacionalização.

O último modelo é por Knight (1994), também com base na abordagem de processo e salientando o processo de internacionalização como um círculo contínuo (WIT, 2002). Embora vários sejam os modelos para a explicação do processo de internacionalização das IES, optou-se pela abordagem de Knight (2004), onde se evidencia a importância de estratégias organizacionais e programáticas como suporte para o processo de internacionalização.

Norfleet et al. (1992) salientam a nova percepção da sociedade contemporânea, através de novas percepções sobre consciência e relações globais, assim como a heterogeneidade comercial em um ambiente cada dia mais competitivo e diversificado. Cabe a cada IES adaptar-se por meio das diferentes estratégias, buscando alianças nacionais e internacionais. As ações utilizadas para internacionalizar as IES podem ser compreendidas como suas estratégias na busca da expansão internacional do conhecimento (KNIGHT, 1999). No entanto, essas ações devem abranger tanto percepções acadêmicas como organizacionais para que sejam bem realizadas (JOFIN, 2009).

As estratégias podem ser descritas e compreendidas como iniciativas organizacionais e programáticas adotadas no nível institucional que são consideradas como um apoio ao processo de internacionalização das IES (KNIGHT, 2004). Knight (2004) salienta que ambas as estratégias, programáticas e organizacionais, são de suma importância para auxiliar a implementação do processo de internacionalização, sendo a falta ou a dissonância de alguma dessas estratégias uma barreira para o restante do processo. Os contextos de novos desafios, segundo Stallivieri (2004):

[...] impelem a universidade a revisar e a atualizar as suas estratégias a fim de que seus estudantes e egressos passem a contar com as competências essenciais acadêmicas e profissionais que lhe permitam interagir numa sociedade cada vez mais multicultural e internacional, com rápidas mudanças em seus sistemas.

O processo de internacionalização de IES está pautado em alguns elementos-chaves que podem ser vistos como facilitadores desse processo e que foram identificados com base em experiências de diferentes universidades. Esses elementos podem ser categorizados como fatores programáticos (acadêmicos) e fatores organizacionais (KNIGHT, 2004). O quadro 1 apresenta um resumo dos elementos mais importantes identificados por diferentes pesquisadores; no entanto, esses elementos não foram classificados inicialmente como subcategorias dos elementos acadêmicos (programáticos) e organizacionais (KNIGHT, 2004). O quadro 2 ilustra uma seleção de estratégias que, para Knight (2004), representam as categorias das estratégias programáticas. No quadro 3, apresentam-se as estratégias programáticas: programas acadêmicos, pesquisa e colaboração acadêmica, relações exteriores e atividades extracurriculares. 
Quadro 1: Estratégias Organizacionais e Programáticas.

\begin{tabular}{|c|c|c|}
\hline Pesquisadores & Elementos Programáticos & Elementos Organizacionais \\
\hline Harari (1989) & $\begin{array}{l}\text { - Desenvolvimento curricular; } \\
\text { - Intercâmbios internacionais; } \\
\text { - Parcerias externas. }\end{array}$ & $\begin{array}{l}\text {-Criação de um ethos internacional no campus; } \\
\text {-Planejamento estratégico integrado; } \\
\text {-Compromisso de liderança superior; } \\
\text {-Apoio interno e alianças externas. }\end{array}$ \\
\hline Audas (1991) & $\begin{array}{l}\text {-Integração do contexto internacional e } \\
\text { intercultural no currículo. }\end{array}$ & $\begin{array}{l}\text {-Políticas escritas a nível central e local; } \\
\text {-Revisão sistemática e planejamento de longo prazo; } \\
\text {-Administração central internacional, com diretor } \\
\text { executivo; } \\
\text {-Canais de comunicação formais e informais. }\end{array}$ \\
\hline Aigner et al. (1992) & $\begin{array}{l}\text {-Currículo } \\
\text {-Língua estrangeira; } \\
\text {-Estágios e intercâmbios internacionais; } \\
\text {-Estudantes e estudiosos estrangeiros; } \\
\text {-Cooperação técnica e desenvolvimento } \\
\text { internacional; } \\
\text {-Serviço público. }\end{array}$ & $\begin{array}{l}\text {-Liderança de administração; } \\
\text {-Capacidade de desenvolvimento e envolvimento; } \\
\text {-Ampla agenda com objetivos específicos; } \\
\text {-Networking; } \\
\text {-Serviço centralizado. }\end{array}$ \\
\hline Norfleet et al. (1992) & $\begin{array}{l}\text {-Recrutamento de estudantes } \\
\text { internacionais; } \\
\text {-Criação de consciência global; } \\
\text {-Internacionalização do currículo; } \\
\text {-Estudo no exterior Intercâmbio de } \\
\text { professores; } \\
\text {-Envolvimento da comunidade. }\end{array}$ & -Compromisso institucional. \\
\hline Scott (1992) & $\begin{array}{l}\text {-Integração através de currículos; } \\
\text {-Inclusão de atividades curriculares e } \\
\text { extracurriculares; } \\
\text {-Ensino de graduação, formação e } \\
\text { investigação; } \\
\text {-Parcerias externas } \\
\text {-Articulação de temas internacionais e } \\
\text { multiculturais. }\end{array}$ & $\begin{array}{l}\text {-Declaração de missão; } \\
\text {-Revisão anual; } \\
\text {-Plano plurianual; } \\
\text {-Captação de recursos; } \\
\text {-Reconhecimento do corpo docente e recompensas; } \\
\text {-Apoio do senado e governantes; } \\
\text {-Fundos para o corpo docente; e desenvolvimento } \\
\text { curricular; } \\
\text {-Metas e objetivos anuais. }\end{array}$ \\
\hline $\begin{array}{l}\text { British Columbia } \\
\text { Centre for International } \\
\text { Education } \\
\text { Francis (1993) }\end{array}$ & $\begin{array}{l}\text {-Currículo; } \\
\text {-Desenvolvimento corpo docente e } \\
\text { funcionários; } \\
\text {-Programa internacional de estudante; } \\
\text {-Estudo/trabalho no exterior e } \\
\text { intercâmbio; } \\
\text {-Projetos internacionais; } \\
\text {-Ligações institucionais; } \\
\text {-Vínculos comunitários. }\end{array}$ & $\begin{array}{l}\text {-Liderança da administração sênior; } \\
\text {-Prioridade para os esforços internacionais; } \\
\text {-Articulação de objetivos; } \\
\text {-Compromisso de longo prazo; } \\
\text {-Relações públicas melhoradas; } \\
\text {-Acesso a recursos; } \\
\text {-Envolvimento do corpo docente; } \\
\text {-Planejamento estratégico e avaliação; } \\
\text {-Recursos. }\end{array}$ \\
\hline Knight (1994) & $\begin{array}{l}\text {-Programas de trabalho/estudo do aluno } \\
\text { no estrangeiro; } \\
\text {-Inovação curricular } \\
\text {-Estudantes e acadêmicos internacionais; } \\
\text {-Intercâmbio do corpo docente e } \\
\text { programas de mobilidade; } \\
\text {-Projetos de desenvolvimento } \\
\text { internacionais; } \\
\text {-Iniciativas de investigação conjuntas; } \\
\text {-Ligações institucionais internacionais; } \\
\text {-Línguas estrangeiras. }\end{array}$ & $\begin{array}{l}\text {-Compromisso e apoio dos administradores seniores e } \\
\text { da Junta de Governadores; } \\
\text {-Apoio e envolvimento da massa crítica de professores } \\
\text { / funcionários; } \\
\text {-Cargo ou função internacional, com pessoal } \\
\text { experiente; } \\
\text {-Financiamento e apoio adequados, tanto interno } \\
\text { como externamente; } \\
\text {-Política de incentivo e apoio a iniciativas locais no } \\
\text { âmbito de uma política institucional ampla; } \\
\text {-Incentivos e recompensas para os alunos, funcionários } \\
\text { e professores; } \\
\text {-Mecanismos de intercâmbio de comunicação e de } \\
\text { informação. }\end{array}$ \\
\hline
\end{tabular}

Fonte: Knight (2004).

Quadro 2: Modelo de Knight - Estratégias Organizacionais.

\begin{tabular}{|l|l|}
\hline \multicolumn{1}{|c|}{ Governança } & \multicolumn{1}{c|}{ Operações } \\
\hline - Compromisso expresso com líderes; & -Integradas ao planejamento, orçamento e sistemas de \\
-Envolvimento ativo do corpo de funcionários; & revisão de qualidade em nível institucional e \\
-Razões e objetivos para a internacionalização bem articulados; & departamental; \\
-Reconhecimento da dimensão internacional na missão, & -Estruturas organizacionais apropriados sistemas \\
planejamento e documentos de política. & formais e informais para a comunicação, ligação e \\
\hline
\end{tabular}




\begin{tabular}{|c|c|}
\hline & $\begin{array}{l}\text { coordenação; } \\
\text {-Equilíbrio entre promoção centralizada e } \\
\text { descentralizada e gestão da internacionalização; } \\
\text {-Apoio financeiro adequado e sistemas de alocação de } \\
\text { recursos. }\end{array}$ \\
\hline Serviços & Recursos Humanos \\
\hline $\begin{array}{l}\text {-Apoio de unidades de serviços da instituição (acomodação para } \\
\text { estudantes, fund raising, tecnologia de informação); } \\
\text {-Envolvimento de unidades de apoio acadêmico (biblioteca, ensino e } \\
\text { aprendizado, desenvolvimento do currículo, treinamento do corpo de } \\
\text { funcionários); } \\
\text {-Serviços de apoio estudantil para estudantes recebidos e enviados: } \\
\text { programas de orientação, conselheiros, treinamento cross cultural, } \\
\text { conselhos sobre vistos. }\end{array}$ & $\begin{array}{l}\text {-Processos de seleção e recrutamento que reconheçam } \\
\text { a experiência internacional; } \\
\text {-Políticas de recompensa e promoção para reforçar } \\
\text { contribuições dos professores e funcionários; } \\
\text {-Atividades de desenvolvimento profissional dos } \\
\text { professores e funcionários; } \\
\text {-Apoio para trabalhos internacionais e concessão de } \\
\text { licenças para fins de estudo. }\end{array}$ \\
\hline
\end{tabular}

Fonte: Knight (2004).

Quadro 3: Modelo de Knight -Estratégias Programáticas.

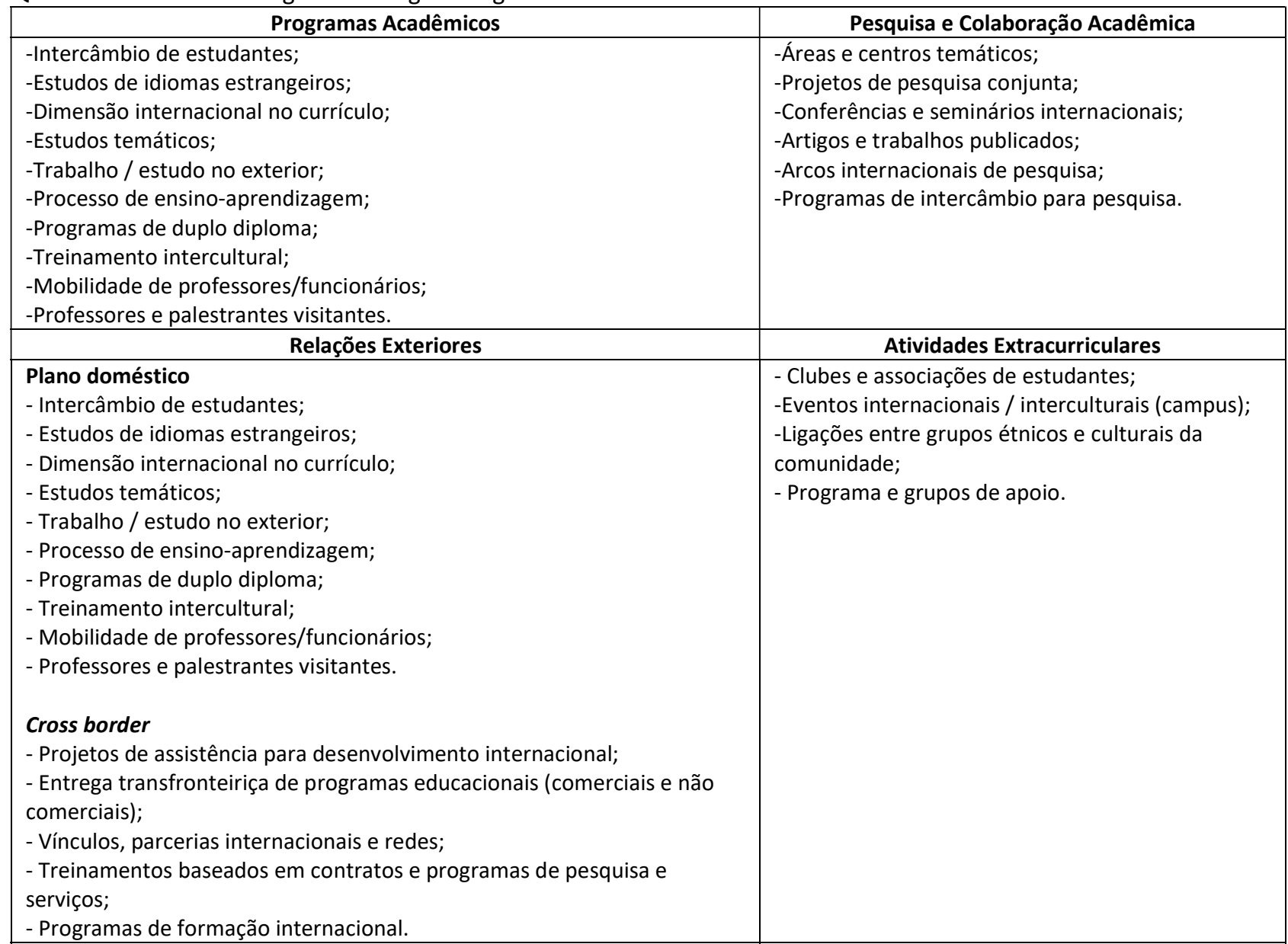

Fonte: Knight (2004).

\section{METODOLOGIA}

Buscou-se investigar quais são as práticas de internacionalização promovidas pela Universidade Federal de Santa Maria. Diante disso, buscando alcançar o objetivo proposto: analisar as práticas de internacionalização promovidas pelos Programas de Pós-Graduação conceitos 6 e 7 da Universidade Federal de Santa Maria, adotou-se um plano de pesquisa de caráter descritivo, quanto aos seus objetivos; qualitativo, quanto à abordagem do problema; e, como delineamento de pesquisa, optou-se pelo estudo de caso.

Neste trabalho, a unidade de análise foi a UFSM. A escolha dessa universidade fundamentou-se em sua importância e representatividade na região sul; conforme a lista de 2015 do QS University Rankings, uma 
organização internacional de pesquisa educacional que avalia o desempenho de instituições de ensino médio, superior e pós-graduação, a UFSM é uma das três universidades do Rio Grande do Sul que aparecem entre as 100 melhores da América Latina. A UFSM está na 89a posição, avançando cinco posições em relação a 2014, quando estava em 94일. lugar. Entre as universidades brasileiras, a UFSM é a 21a colocada.

Optou-se por investigar os programas de pós-graduação conceitos 6 e 7 avaliados pela CAPES, por permitirem um estudo mais aprofundado da temática de internacionalização, uma vez que já apresentam desempenho internacional. Para o desenvolvimento deste estudo, foram realizadas entrevistadas com 6 (seis) profissionais que atuam em diferentes áreas da Universidade Federal de Santa Maria, incluindo o ViceReitor, assim como o Pró-Reitor de Graduação, o Assessor da Secretaria de Apoio Internacional e os Coordenadores dos Programas de Pós-Graduação de Engenharia Elétrica, Química e Medicina Veterinária, por possuem conceitos 6 e 7 avaliados pela CAPES. Utilizou-se como critério de seleção dos entrevistados, o contato com o processo de internacionalização da UFSM, sendo considerados informantes chave desse processo.

Cabe salientar que, antes da realização das entrevistas, entrou-se em contato com cada participante por meio de e-mails em que foi enviado um convite para participação nesta pesquisa, com esclarecimentos sobre os objetivos do estudo. Mediante aceite em participar da pesquisa, foram agendados horários para a realização das entrevistas, que ocorreram nas coordenações de cada programa de pós-graduação, assim como na reitoria da UFSM. As entrevistas foram protocoladas e gravadas mediante autorização de cada entrevistado. A duração das entrevistas variou entre 40 minutos e duas horas e trinta minutos, em um período de 4 meses. Destaca-se ainda o total apoio e colaboração dos entrevistados para a realização das etapas da pesquisa.

Os dados coletados nas entrevistas necessitaram de tratamento prévio, a fim de facilitar a interpretação e a relação com as categorias de análise que o modelo teórico-conceitual adotado estabelece. Como técnica de interpretação adotou-se a análise de conteúdo, que busca auxiliar o pesquisador na descrição, interpretação e compreensão das informações disponíveis nas mais diversas classes (MORAES, 1999). É importante ressaltar que a análise de conteúdo se baseia na interpretação do pesquisador a respeito dos dados obtidos.

A análise de conteúdo foi disposta sob três fases: a pré-análise, a exploração do material e o tratamento dos resultados, inferência e interpretação (BARDIN, 2006). Primeiramente houve a pré-análise do áudio das entrevistas, havendo posteriormente a transcrição dessas entrevistas. A exploração do material envolveu a classificação dos dados coletados nas entrevistas, os quais foram sistematizados em categorias de análise classificadas como razões; ações; estratégias organizacionais e programáticas que envolveram o processo de internacionalização da UFSM; posteriormente houve o tratamento dos resultados, sendo interpretados segundo as informações teóricas disponíveis ao pesquisador.

\section{RESULTADOS E DISCUSSÃO}

A UFSM tem demonstrado inserção internacional desde a década de 1990, primeiramente nas áreas 
de Medicina Veterinária, Direito e Engenharias. Os coordenadores do Programa de Pós-Graduação em Medicina Veterinária, assim como do Programa de Pós-Graduação em Química e do Programa de PósGraduação em Engenharia Elétrica convergem a respeito da questão de a internacionalização ainda ser complexa, acreditando que boa parte dos programas de conceitos 6 e 7 não consiga exercer a internacionalização no seu âmbito máximo, pois acreditam que os PPG buscam a internacionalização com ações particulares de cada programa. A tabela 1 sintetiza os resultados sobre as razões e ações do processo de internacionalização da UFSM. Os resultados das estratégias organizacionais e programáticas adotados pela UFSM no processo de internacionalização estão sintetizados no quadro 4.

Tabela 1: Razões e ações do processo de internacionalização da UFSM.

\begin{tabular}{|c|c|}
\hline \multirow{4}{*}{$\begin{array}{c}\text { Razões que } \\
\text { impulsionaram o } \\
\text { processo de } \\
\text { internacionalização da } \\
\text { UFSM }\end{array}$} & Busca do desenvolvimento da educação e da economia, por meio da cooperação acadêmica; \\
\hline & Desenvolvimento de projetos que beneficiem professores, pesquisadores, alunos da instituição; \\
\hline & Implementação de programas de cooperação técnico-científica e cultural; \\
\hline & Intercâmbio de conhecimento e troca de informações e materiais. \\
\hline \multirow[t]{2}{*}{$\begin{array}{l}\text { Ações desenvolvidas pela } \\
\text { UFSM em prol da } \\
\text { internacionalização }\end{array}$} & $\begin{array}{l}\text { A UFSM possui convênios com } 129 \text { instituições internacionais e } 1250 \text { convênios com instituições } \\
\text { nacionais. }\end{array}$ \\
\hline & $\begin{array}{l}\text { E laços estabelecidos com o Grupo Coimbra e a AUGM - Associação de Universidades Grupo } \\
\text { Montevidéu. }\end{array}$ \\
\hline
\end{tabular}

Quadro 4: Estratégias organizacionais e programáticas adotadas pela UFSM no processo de internacionalização.

\begin{tabular}{|c|c|}
\hline \multicolumn{2}{|r|}{ Estratégias Organizacionais } \\
\hline Governança & $\begin{array}{l}\text { Existe a necessidade de que os objetivos e as razões para a internacionalização sejam mais claros e } \\
\text { articulados com a missão, visão e valores da instituição, pois ainda não há, no Plano de Gestão da } \\
\text { Universidade, um eixo referente às políticas de internacionalização, sendo ainda muito incipientes os } \\
\text { planejamentos referentes à estruturação da universidade a nível internacional. }\end{array}$ \\
\hline Operações & $\begin{array}{l}\text { Atualmente a UFSM conta com a SAI para a operacionalização do processo de internacionalização. Está } \\
\text { em fase de implantação, a centralização e informatização das informações sobre a mobilidade discente e } \\
\text { docente, estabelecimento de acordos e convênios e demais informações de interesse acadêmico. }\end{array}$ \\
\hline Serviços & $\begin{array}{l}\text { A UFSM dispõe de ampla infraestrutura em seu campus na Cidade de Santa Maria, visando a atender } \\
\text { adequadamente e com qualidade seus estudantes. Contudo, ainda se percebe a necessidade de } \\
\text { adequação nas estruturas relacionadas à questão internacional, como a Secretária de Apoio Internacional, } \\
\text { que conta com apenas quatro funcionários, que atuam na formalização de convênios internacionais, na } \\
\text { divulgação da imagem da universidade, no fomento e na promoção para que os professores e } \\
\text { pesquisadores interajam com outros cursos. }\end{array}$ \\
\hline Recursos Humanos & $\begin{array}{l}\text { Ainda não há, na UFSM, um processo seletivo que reconheça a experiência internacional dos candidatos; } \\
\text { entretanto, também não há políticas de recompensa e promoção para reforçar as contribuições dos } \\
\text { professores e funcionários, uma vez que existe isonomia salarial na instituição, tanto para técnicos } \\
\text { administrativos como para professores. }\end{array}$ \\
\hline \multicolumn{2}{|r|}{ Estratégias Programáticas } \\
\hline $\begin{array}{l}\text { Programas } \\
\text { Acadêmicos }\end{array}$ & $\begin{array}{l}\text { A UFSM possui associações e convênios com instituições estrangeiras que possibilitam o intercâmbio de } \\
\text { alunos em busca de crescimento e desenvolvimento pessoal e profissional, a fim de preparar seus alunos } \\
\text { para o exterior; disponibiliza cursos de inglês, para que o idioma não seja uma barreira. Quanto à } \\
\text { dimensão internacional do currículo para seleção do aluno, ainda está em estudo a inserção dessa } \\
\text { modalidade nos editais de seleção. As modalidades de duplo diploma e cotutela segundo os entrevistados } \\
\text { ainda não são exercidas pela UFSM, entretanto, segundo a Resolução N. } 027 / 2014 \text { de } 25 \text { de novembro de } \\
\text { 2014, foi regulamentado o procedimento interno de Cotutela de Dissertação e Tese referente a diploma } \\
\text { com titulação simultânea em dois países. }\end{array}$ \\
\hline \multirow[t]{2}{*}{$\begin{array}{l}\text { Pesquisa e } \\
\text { Colaboração } \\
\text { Acadêmica }\end{array}$} & $\begin{array}{l}\text { A UFSM possui projetos de pesquisa conjunta com diversas universidades estrangeiras, a fim de promover } \\
\text { e estimular o ensino e os avanços científico-pedagógicos entre os dois países, incrementando o } \\
\text { intercâmbio e a cooperação técnico-científica, com o objetivo de fortalecer a pesquisa científica } \\
\text { institucional e os programas de desenvolvimento. }\end{array}$ \\
\hline & $\begin{array}{l}\text { Plano Doméstico } \\
\text { A UFSM é parceira de instituições nacionais públicas e privadas, a fim de buscar crescimento e } \\
\text { cooperativismo junto a essas organizações, sendo mais de } 1200 \text { convênios formalizados, segundos dados }\end{array}$ \\
\hline
\end{tabular}




\begin{tabular}{|c|l|}
\hline \multirow{5}{*}{ Relações Exteriores } & $\begin{array}{l}\text { da SAI, 2015. Os dados da SAI demonstram que a coordenação dos convênios está intimamente ligada } \\
\text { aos programas de pós-graduação e aos departamentos, não sendo diretamente desenvolvido e } \\
\text { coordenado pela reitoria, pois esses convênios requerem o desenvolvimento de atividades constantes, o } \\
\text { que só poderá ser desenvolvido pelos responsáveis pela abertura do convênio. }\end{array}$ \\
\cline { 2 - 3 } & $\begin{array}{l}\text { Cross border (Transfronteiriça) } \\
\text { Basicamente, a UFSM dispõe de vínculos internacionais e redes internacionais com o Grupo Coimbra e a } \\
\text { AUGM e demais convênios em andamento. A assistência e o incentivo para o desenvolvimento } \\
\text { internacional ainda são rudimentares, sendo percebido pela falta de disseminação sobre a } \\
\text { internacionalização, convênios e associações disponíveis para pesquisa e intercâmbio. }\end{array}$ \\
\hline \multirow{2}{*}{ Atividades } & $\begin{array}{l}\text { As atividades extracurriculares desenvolvidas na UFSM são de cunho internacional, nacional e regional, } \\
\text { envolvendo eventos como seminários, jornadas acadêmicas e semanas acadêmicas, integrando os alunos } \\
\text { de outras instituições e, muitas vezes, estudantes estrangeiros de instituições estrangeiras, possibilitando } \\
\text { assim, novas experiências e contato com novas culturas e saberes. A UFSM desempenha intuitivamente } \\
\text { peer support, ou seja, alunos que falam fluentemente determinando idioma prestam apoio a alunos } \\
\text { estrangeiros. A instituição não dispõe de programa ou grupos especializados nesse apoio entre colegas. }\end{array}$ \\
\hline
\end{tabular}

CONCLUSÕES

A internacionalização na UFSM, instituição estudada, é vista como um processo contínuo, não findo. Entretanto, para que esse processo tenha sucesso, é preciso que todas as partes envolvidas estejam em sintonia e, segundo os dados obtidos com a pesquisa, a internacionalização ainda é vista como atividade isolada, partindo dos pesquisadores a vontade de internacionalizar. Vale ressaltar que a universidade em si não faz internacionalização sozinha, ela existe e tem nome por meio de seus profissionais, não cabendo apenas à reitoria firmar convênios, se não são atuados pelos pesquisadores. Ficam claras as necessidades expostas pelos entrevistados sobre a consolidação e desenvolvimento de políticas e estratégias organizacionais e programáticas concisas, articuladas com os demais departamentos da universidade, conforme modelo de Knight (2004).

No tocante às estratégias organizacionais, compreende-se a necessidade de tecer melhores práticas para o processo de internacionalização, referente às categorias de governança, operações e serviços, evidenciadas no posicionamento dos entrevistados. Houve reconhecimento da busca da UFSM pela inserção internacional, por meio de atividades de desenvolvimento profissional de professores e funcionários, assim como apoio para trabalhos internacionais e concessão de licenças para fins de estudo.

Em relação às estratégias programáticas, a universidade tem realizado um número maior de ações, embora ainda não amplamente satisfatórias. Nas categorias de relações exteriores e atividades extracurriculares, a UFSM ainda necessita maior desenvolvimento dessas atividades, entretanto atende de maneira satisfatória a mobilidade discente e docente, desenvolvendo pesquisas conjuntas com universidades estrangeiras, embora não seja algo unânime em todos os programas de pós-graduação.

As grandes limitações desse processo podem ser consideradas as estruturas da universidade, com estrutura insuficiente na SAI, contando com poucos funcionários e espaço físico restrito. Outro obstáculo à internacionalização é o idioma, uma vez que a universidade ainda não possui estrutura física específica, como um centro de idiomas para dispor de cursos de aperfeiçoamento e treinamento de funcionários, esbarrando na dificuldade da inserção do aluno estrangeiro na rotina universitária, mas participa do Idiomas sem Fronteira possibilitando ao aluno que tem interesse em aprender outro idioma, participar gratuitamente dos cursos.

A disponibilidade dos dados referentes à internacionalização da UFSM, como mobilidade acadêmica, 
convênios entre universidades e pesquisas conjuntas ainda não estão sistematizados em apenas um local e ainda não estão informatizados, pois a SAl está em processo de organização desses dados. Contudo, houve um avanço bastante significativo na formalização de convênios internacionais entre os anos 2009 e 2012, com ápice no ano de 2012, após a criação do Programa Ciência sem Fronteiras, que ocorreu em julho de 2011.

Espera-se profundamente que a UFSM siga reconhecida pela busca do crescimento e aperfeiçoamento contínuo, aprimorando processos e ampliando ainda mais seus laços regionais, nacionais e internacionais, buscando assim incorporar, em sua cultura organizacional, o princípio internacional. As contribuições acadêmicas desta pesquisa envolvem o desempenho internacional da Universidade Federal de Santa Maria, descrevendo as razões, ações, e estratégias, deste processo de internacionalização, afim de que se possa efetivamente construir e implementar políticas direcionadas à internacionalização, mantendo ações assertivas e apropriadas e corrigindo o que ainda está falho.

Quanto às contribuições práticas, o estudo almejou contribuir na identificação da situação internacional da UFSM de maneira parcial, uma vez que a literatura dispõe de modelos que podem complementar esse mapeamento das práticas utilizadas e das ainda não implementadas na instituição. Espera-se que tal mapeamento seja um facilitador da análise das potencialidades e fragilidades da UFSM no cenário internacional, favorecendo as decisões e articulações das metas, missão e políticas da UFSM.

A pesquisa apresenta limitações quanto à abordagem de estudo de caso, uma vez que os estudos de casos não são capazes de uma generalização científica, entretanto, o estudo de caso apresentado neste trabalho buscou estudar um contexto específico, evidenciando um tema pouco explorado na Universidade Federal de Santa Maria. A pesquisa de campo poderia ter tido um número maior de entrevistados, sendo a principal dificuldade a cooperação e apoio no agendamento das entrevistas, havendo dificuldades na disponibilização de documentos complementares para a pesquisa, uma vez que a SAl não dispunha de materiais compilados adequadamente para fornecimento de dados.

As recomendações para pesquisas futuras envolvem a possibilidade de comparar o processo de internacionalização da UFSM com universidades estrangeiras, com as quais a UFSM possui convênios; assim como, um comparativo com universidades nacionais, com processo de internacionalização avançado, buscando um benchmarking de seus processos, assim como a utilização de modelos mais amplos para o mapeamento do processo de internacionalização da UFSM o qual possa trazer a evolução da mobilidade discente da universidade, não apenas nos programas com conceito Capes 6 e 7, mas também de programas ainda não amplamente internacionalizados.

\section{REFERÊNCIAS}

AIGNER, J. S.; NELSON, P. N.; STIMPFL, J.. Internationalizing the university: making it work. Springfield: CBIES Federal, 1992.

AKKARI, A.. Internacionalização das políticas educacionais: transformações e desafios. Petrópolis: Vozes, 2011.
AUDAS, M.. Comparing Policy Statements and Practices in the International Dimension of Selected Institutions of Higher Education. International Education Forum, v.11, n.2, 1991.

BARDIN, L.. Análise de conteúdo. Lisboa: 70, 2006. 
CAPES. Avaliação Trienal 2013. CAPES, 2013.

CARNOY, M.. Mundialização e reforma na educação superior: o que os planejadores devem saber. Brasília: UNESCO, 2002

GOODSON, I. F.. Estudio del curriculum: casos Y métodos. Buenos Aires: Amorrortu, 2003.

HARARI, M.. Internationalization of Higher Education: Effecting Institutional Change in the Curriculum and Campus. Long Beach: Center for International Education, California State University, 1989.

ILLICH, I.. Deschooling society. Nova York: Harper e Row, 1970.

JOFIN, J.. Internationalization of Higher Education: an evaluative study of internationalization efforts at the Dissertation (Master's) - University of Chester, Londres, 2009.

KNIGHT, J.. An internationalization model: responding to new realities and challenges. In: WIT, H.; JARAMILO, I. C.; GARCEL-AVILA, J.; KNIGHT, J.. Higher education in Latin America: the international dimension. Washington: World Bank, 2005.

KNIGHT, J.. Internacionalização da educação superior: novos desenvolvimentos e consequências não intencionadas. Boletim lesalc, 2010.

KNIGHT, J.. Internationalization: Elements and checkpoints. Ottawa: Canadian Bureau for International Education, 1994.

KNIGHT, J.. Internationalization of Higher Education. In: KNIGHT, J.; WITT, H.. Quality and Internationalization in Higher. Paris: IMEH, 1999.

KNIGHT, J.. Internationalization Remodeled: Definition, Approaches, and Rationales. Journal of Studies in International Education, v.8, n.1, 2004.

LÉVY, P.. Cibercultura. 34 ed. São Paulo, 1999.

MIURA, I. K.. O processo de internacionalização da universidade de São Paulo. Um estudo de três áreas do conhecimento. Tese (Doutorado em Administração) Universidade de São Paulo, Ribeirão Preto, 2006.

MORAES, R.. Análise de conteúdo. Revista Educação, Lisboa, v.9, n.37, p.7-32, 1999.
NEVES, C. E. B.. O Processo de Bolonha e as transformações dos sistemas de educação superior na Europa. 2007.

NORFLEET, L.; WILCOX, B.. Internationalizing College

Campuses. Washington: American Association of

Community Junior Colleges, 1992.

OLIVEIRA, J. F.. A Reestruturação da educação superior no Brasil e o processo de metamorfose das universidades federais: o caso da Universidade Federal de Goiás (UFG). Tese (Doutorado) - Universidade de São Paulo, São Paulo, 2000.

SANTOS, F. S.; ALMEIDA, N. F.. A quarta missão da universidade: Internacionalização universitária na sociedade do conhecimento. Brasília: UNB, 2012.

SCHRIEWER, J.. L'internationalisation des discours sur l'education: adoption d'une idéologie mundiale ou persistence du style de réflexion systémique spécifiquement nationale?. Revue Francaise de Pédagogie, n.146, p.7-26, 2004.

SCOTT, R. A.. Campus Developments in Response to the Challenges of Internationalization: The Case of Ramapo College of New Jersey (USA). Springfield: CBIS Federal Inc., 1992.

STALLIVIERI, L.. Estratégias de Internacionalização das Universidades Brasileiras. Caxias do Sul: Educs, 2004.

TAYLOR, J.. The Management of Internationalization in Higher Education. Raabe: Internationalization of European Higher Education, 2010.

UNESCO. Educação superior: reforma, mudança e internacionalização. Brasília: UNESCO, 2003.

UNESCO. Internationalization of higher education: An institutional perspective. Bucharest: UNESCO, 2000.

VAN DER WENDE, M.. Missing links: the relationship between national policies for internationalization and those for higher education in general e International comparative analysis and synthesis. In: KÄLVEMARK, T.; VAN DER WENDE, $M$.. National Policies for the Internationalization of Higher Education in Europe. Stockholm: National Agency for Higher Education, 1997.

WIT, H.. Internationalization of higher education in the United States of America and Europe: a historical, comparative, and conceptual analysis. British Library Cataloguing in Publication, 2002.

A CBPC - Companhia Brasileira de Produção Científica (CNPJ: 11.221.422/0001-03) detém os direitos materiais desta publicação. Os direitos referem-se à publicação do trabalho em qualquer parte do mundo, incluindo os direitos às renovações, expansões e disseminações da contribuição, bem como outros direitos subsidiários. Todos os trabalhos publicados eletronicamente poderão posteriormente ser publicados em coletâneas impressas sob coordenação da Sustenere Publishing, da Companhia Brasileira de Produção Científica e seus parceiros autorizados. Os (as) autores (as) preservam os direitos autorais, mas não têm permissão para a publicação da contribuição em outro meio, impresso ou digital, em português ou em tradução. 